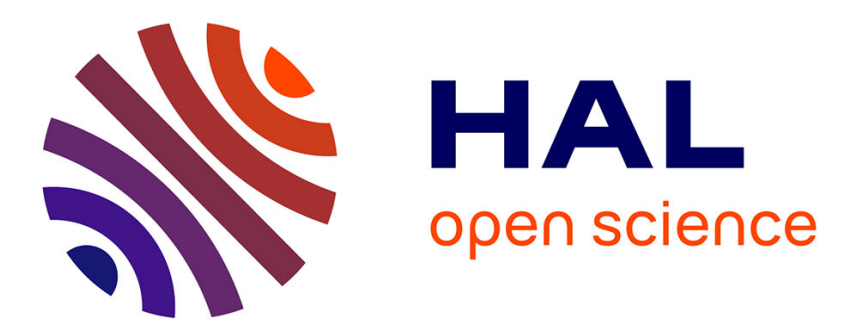

\title{
Convective and shear-induced turbulence in the deep Kane Gap
}

\author{
H. van Haren, E. Morozov, Louis Gostiaux, Roman Tarakanov
}

\section{To cite this version:}

H. van Haren, E. Morozov, Louis Gostiaux, Roman Tarakanov. Convective and shear-induced turbulence in the deep Kane Gap. Journal of Geophysical Research. Oceans, 2013, 118 (11), pp.5924-5930. 10.1002/2013JC009282 . hal-00880518

\section{HAL Id: hal-00880518 https://hal.science/hal-00880518}

Submitted on 13 Apr 2016

HAL is a multi-disciplinary open access archive for the deposit and dissemination of scientific research documents, whether they are published or not. The documents may come from teaching and research institutions in France or abroad, or from public or private research centers.
L'archive ouverte pluridisciplinaire HAL, est destinée au dépôt et à la diffusion de documents scientifiques de niveau recherche, publiés ou non, émanant des établissements d'enseignement et de recherche français ou étrangers, des laboratoires publics ou privés. 


\title{
Convective and shear-induced turbulence in the deep Kane Gap
}

\author{
Hans van Haren, ${ }^{1}$ Eugene Morozov, ${ }^{2}$ Louis Gostiaux, ${ }^{3}$ and Roman Tarakanov ${ }^{2}$ \\ Received 16 July 2013; revised 7 October 2013; accepted 8 October 2013; published 5 November 2013.
}

[1] The boundary layer above a $4569 \mathrm{~m}$ deep slope in the near-equatorial N-Atlantic Ocean Kane Gap, a throughflow for Antarctic Bottom Water (AABW), is characterized by two distinct turbulent regimes that differ by an order of magnitude in intensity depending on the direction of throughflow. During southward and downward flow, vertical mixing is vigorous. This is inferred from high-resolution temperature observations between 6 and $132 \mathrm{~m}$ above the bottom. For a representative case study of 2 days, average values are found for dissipation rate of $\varepsilon=2.1 \pm 1 \times 10^{-9} \mathrm{~W} \mathrm{~kg}^{-1}$ and eddy diffusivity of $\mathrm{K}_{\mathrm{z}}=7 \pm 4 \times$ $10^{-4} \mathrm{~m}^{2} \mathrm{~s}^{-1}$. The mixing is across relatively large vertical overturns. During northward and upward flow, smaller overturns are more horizontal as in stratified shear flow (with representative 2 day mean $\varepsilon=6 \pm 3 \times 10^{-11} \mathrm{~W} \mathrm{~kg}^{-1}, \mathrm{~K}_{\mathrm{z}}=4 \pm 2 \times 10^{-5} \mathrm{~m}^{2} \mathrm{~s}^{-1}$ ). Stratification is approximately the same during both flow directions. Although the different turbulence regimes are partially associated with frictional boundary layers of large-scale flows above sloping topography, but not with those over flat bottoms, and partially with flow across a hill-promontory, internal waves are a dominant process in promoting turbulence. In addition, internal waves are observed to push stratification toward the bottom thereby importantly contributing to the mixing of AABW.

Citation: van Haren, H., E. Morozov, L. Gostiaux, and R. Tarakanov (2013), Convective and shear-induced turbulence in the deep Kane Gap, J. Geophys. Res. Oceans, 118, 5924-5930, doi:10.1002/2013JC009282.

\section{Introduction}

[2] The flow through passages in large underwater topography like the Mid-Atlantic Ridge are of importance for the transport of water masses, in particular Antarctic Bottom Water (AABW), see Figure 1 (inset). During its northward transport, AABW passes through the Mid-Atlantic Ridge's Romanche, Chain and Vema Fracture Zones to reach the East-Atlantic Basins [Morozov et al., 2010]. The passage from the near-equatorial East-Atlantic Guinea Basin to the more northerly Gambia Abyssal Plain and Canary Basin is Kane Gap. Peculiarly, AABW is found to Kane Gap's south, coming from the Romanche and Chain Fracture Zones, and to its north, coming from the Vema Fracture Zone. The temperature (density) difference between the basins at either side of the Kane Gap are quite small $\left(\sim 0.01^{\circ} \mathrm{C}\right)$ near the bottom [Morozov et al., 2010].

\footnotetext{
${ }^{1}$ Royal Netherlands Institute for Sea Research (NIOZ), Den Burg, Texel, the Netherlands.

${ }^{2}$ Shirshov Institute of Oceanology, Russian Academy of Sciences, Moscow, Russia.

${ }^{3}$ Laboratoire de Mécanique des Fluides et d'Acoustique, École Centrale de Lyon, Université de Lyon, Écully cedex, France.

Corresponding author: H. van Haren, Royal Netherlands Institute for Sea Research (NIOZ), P.O. Box 59, 1790 AB Den Burg, Texel, the Netherlands. (hans.van.haren@nioz.nl)

(C) 2013. American Geophysical Union. All Rights Reserved. 2169-9275/13/10.1002/2013JC009282
}

Although the mean flow through the Kane Gap is almost negligible, as shown in the data to be presented here, little is known about variations in currents and the cause thereof.

[3] In this paper, we study vertical mixing processes using yearlong moored high-resolution temperature observations in the range between 6 and $132 \mathrm{~m}$ above the bottom (mab) of the Kane Gap's AABW. As will be demonstrated, these mixing processes vary strongly depending on the flow direction through the Kane Gap.

[4] The mooring is located on the western slope of Kane Gap and just south of a small hill (Figure 1). From previous observational studies and supporting theory in other, mainly shallower, areas, we expected for such a mooring location above sloping topography: (a) southward flow to cause downwelling and enhanced turbulence due to static instability with reduced stratification [Weatherly and Martin, 1978; Lentz and Trowbridge, 1991; Garrett et al., 1993; Hosegood and van Haren, 2003], (b) northward flow to cause upwelling and suppressed turbulence with increased stratification [Weatherly and Martin, 1978; Garrett et al., 1993], (c) solibores to form and contribute to mixing as modeled and observed in $\sim 100 \mathrm{~m}$ shallow waters [Vlasenko and Hutter, 2002; Klymak and Moum, 2003] and $\sim 3000 \mathrm{~m}$ deep waters [Bonnin et al., 2006], (d) bedgenerated turbulence to affect mixing close to the seabed, and (e) evidence of hydraulic jumps and solitary waves in the flow near the hill and constriction to be found [Hibiya, 1988]. None of these effects were observed as a single dominant process in the present data. 


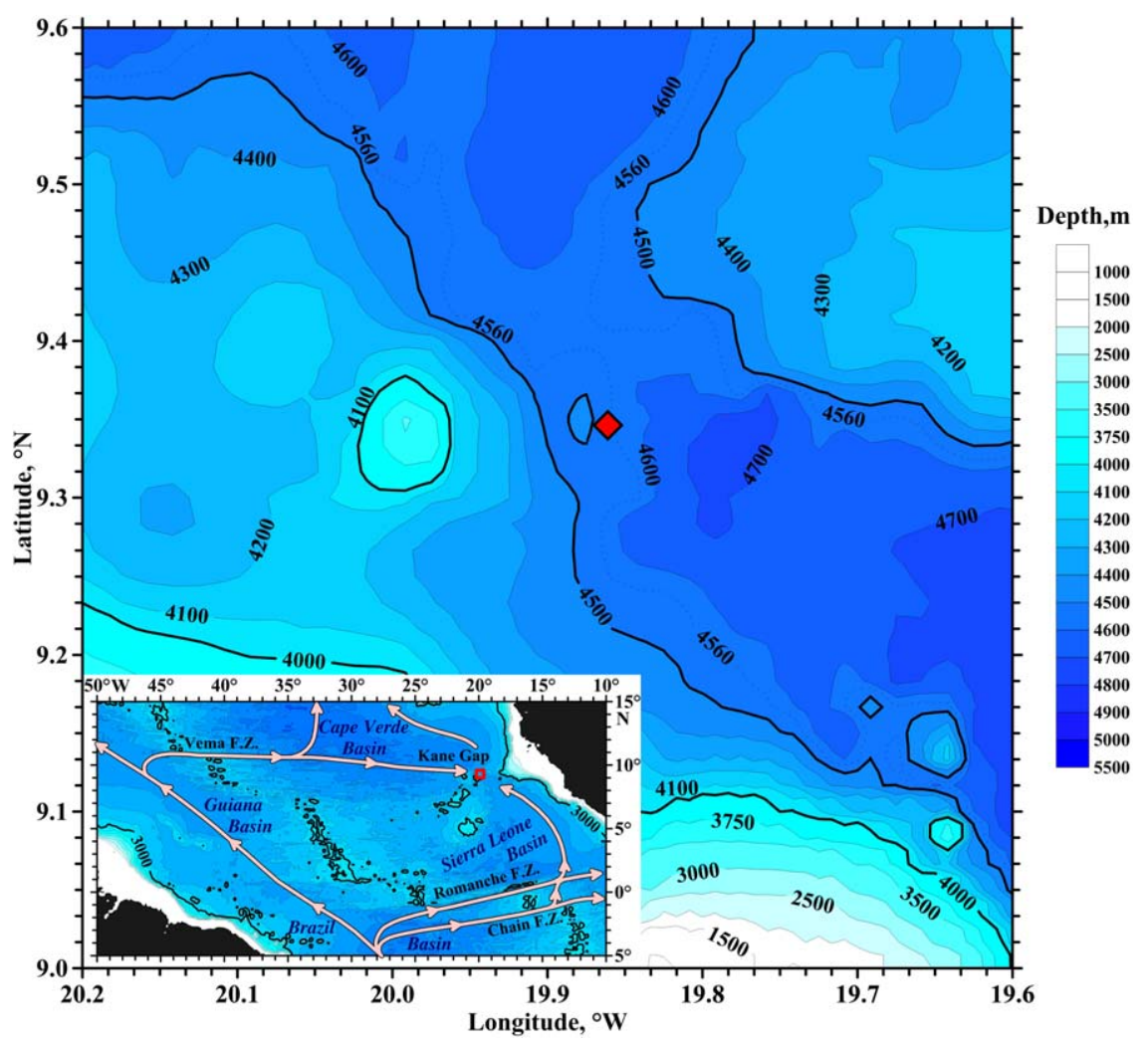

Figure 1. Mooring location (red diamond) in the near-equatorial Kane Gap, NE Atlantic Ocean. Depths from a 1' database [Smith and Sandwell, 1997] and corrected with echo-sounder data. The bottom consists of muddy sediment. In the inset, the inferred flow of AABW is indicated, with main conduits the Romanche, Chain and Vema Fracture Zones crossing the Mid-Atlantic Ridge [Morozov et al., 2010]. This leads to an AABW approach of the Kane Gap from both the south and the north.

\section{Materials and Methods}

[5] A total of 63 "NIOZ3" self-contained temperature (T) sensors sampling at $1 \mathrm{~Hz}$, with precision better than $0.001^{\circ} \mathrm{C}$ [van Haren et al., 2009], were mounted at $2.0 \mathrm{~m}$ vertical intervals on a $0.009 \mathrm{~m}$ diameter nylon coated steel cable. The sensors were synchronized every $6 \mathrm{~h}$ through induction, so that the $125 \mathrm{~m}$ high profile is measured quasiinstantaneously, with a delay of $<0.04 \mathrm{~s}$. The lowest sensor was 6 mab. The $205 \mathrm{~m}$ long cable was between two Nortek AquaDopp current meters sampling once every $600 \mathrm{~s}$. A third current meter was attached in the middle of the cable. Approximately $300 \mathrm{~kg}$ net buoyancy on top ensured mooring deflection to be $<0.4 \mathrm{~m}$ at the upper current meter under maximum $0.25 \mathrm{~m} \mathrm{~s}^{-1}$ current speeds. The line was moored at $09^{\circ} 20.178^{\prime} \mathrm{N},-19^{\circ} 52.454^{\prime} \mathrm{W}, 4569 \mathrm{~m}$ water depth, in the near-equatorial NE Atlantic Ocean (Figure 1) between October 2010 and October 2011. The nearby actual passage of the Kane Gap is oriented (north-)northwest (NNW)-(south-)southeast (SSE), but locally near the mooring the bottom topography is directed practically N-S, and even slightly NNNE-SSSW. The mooring anchor was at the same depth as the shallowest point of the passage and about $70 \mathrm{~m}$ deeper than a hill-promontory along the slope to its northwest.

[6] After applying predeployment calibration information, the T-data are corrected for small drift over 4 day windows by fitting to linear profiles that are restricted to within the values of the CTD profiles which were obtained immediately before and after the mooring period. The corrected T-data are transferred to conservative ( $\sim$ potential $)$ temperature $\Theta$. Lacking salinity data, the $\Theta$ are used as a conservative estimate for potential density variations $\left(\delta \sigma_{4000}\right)$ that are referenced to $4000 \mathrm{~m}$, using the relation $\delta \sigma_{4000}=\alpha \delta \Theta$, with $\alpha=-0.12 \pm 0.005 \mathrm{~kg} \mathrm{~m}^{-3}{ }^{\circ} \mathrm{C}^{-1}$ (Figure 2). For this relationship, the value of $\alpha$ is computed by linear best fit from the average of three CTD profiles near the mooring site for the $200 \mathrm{~m}$ range of moored observations.

[7] Vertical eddy diffusivity $\mathrm{K}_{\mathrm{z}}$ and kinetic energy dissipation rate $\varepsilon$ are estimated by calculating "overturning" scales using moored $\Theta$. These scales are obtained after reordering for every $1 \mathrm{~Hz}$ time step the potential density $(\Theta)$ profile, which may contain inversions, into a stable monotonic profile without inversions [Thorpe, 1977, 1987]. After comparing raw and reordered profiles, displacements (d) are calculated that generate the stable profile beyond a certain threshold [Galbraith and Kelley, 1996]. As $\Theta$ are obtained from a set of 63 independent sensors of which instrumental noise is very low $\left(4 \times 10^{-5 \circ} \mathrm{C}\right)$, the threshold depends on the remaining temperature shifts after calibration, $\sim 3 \times 10^{-4 \circ} \mathrm{C}$ in this case [van Haren et al., 2009]. Then, $\varepsilon=0.64 \mathrm{~d}^{2} N^{3}$, where $N$ denotes the buoyancy frequency computed from the reordered profile over $\Delta z=2 \mathrm{~m}$ vertical intervals and the constant follows from empirically relating the (rms) displacement scale with the Ozmidov 

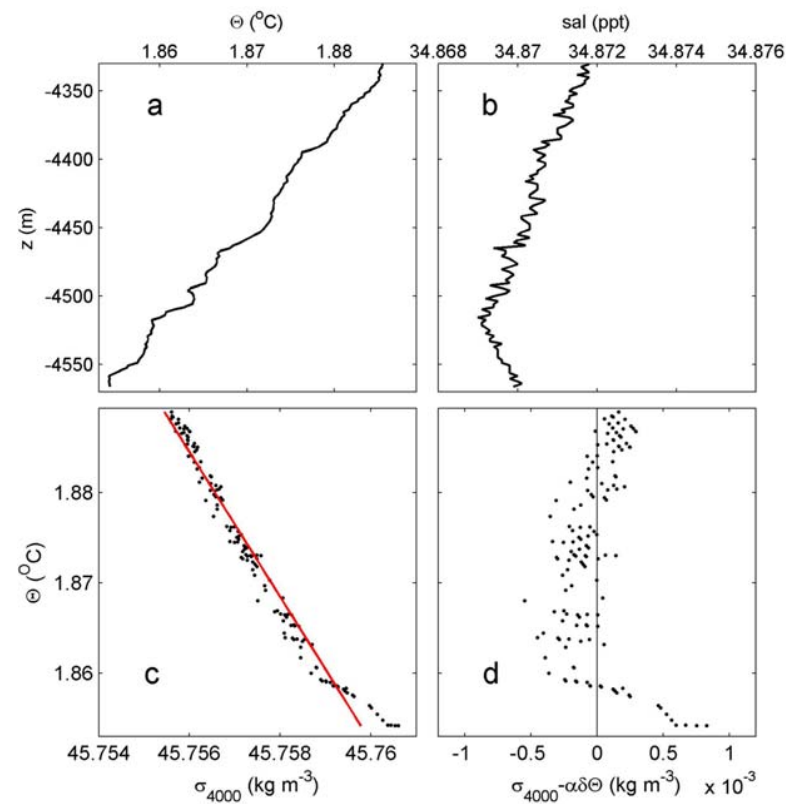

Figure 2. CTD observations just prior to deployment of the mooring, over the lower $220 \mathrm{~m}$ above the bottom: (a) conservative temperature, (b) salinity, (c) density anomaly (referenced to $4000 \mathrm{~m}$ )-Conservative temperature relationship, and (d) goodness of fit (dotted observations in plot Figure 2c-red line fit).

scale $\mathrm{L}_{\mathrm{O}}=0.8 \mathrm{~d}$ [Dillon, 1982]. The resolvable threshold averaged over the entire vertical range is $\sim 10^{-12} \mathrm{~W} \mathrm{~kg}^{-1}$. Using $\mathrm{K}_{\mathrm{z}}=\Gamma \varepsilon \mathrm{N}^{-2}$ and a mixing efficiency for conversion of kinetic into potential energy of $\Gamma=0.2$ [Osborn, 1980; Oakey, 1982], we find $\mathrm{K}_{\mathrm{z}}=0.128 \mathrm{~d}^{2} N$.

[8] In the following, averaging over time is denoted by $[\ldots]$, averaging over depth by $\langle\ldots\rangle$.

\section{Observations}

[9] The yearlong time series of currents and temperature show a distinct variation between "northward (N-)" and "southward (S-)" flow, as defined from the average over the three current meters. Initially, flow varies direction about every 90 days and in the second half of the observational period about every 45 days (Figures $3 a-3 c$ and 4 ). Current amplitudes reach up to $0.25 \mathrm{~m} \mathrm{~s}^{-1}$, but the yearlong mean flow is rather weak: $[\langle\mathrm{u}, \mathrm{v}\rangle]=-0.015,-0.002$ $\mathrm{m} \mathrm{s}^{-1}$, hence slightly downslope and southward. Although the Kane Gap's main topography suggests a throughflow direction of NNW-SSE, the observed current's standard deviation suggests a slightly different local direction: $-12^{\circ},-4^{\circ}$, and $+29^{\circ}$ for currents at 7,111 , and $210 \mathrm{mab}$, respectively. Thus, in the following the "average" N-S (and E-W) axes of local coordinate system are used for horizontal current components $\mathrm{v}$ (and $\mathrm{u})$.

[10] During "N-flow," e.g. between days 475 and 520, waters are about $0.01^{\circ} \mathrm{C}$ cooler than average at a given depth (Figure 3c). On average, the flow is equal to or smaller than a crudely estimated mode-1 (within the range of observations) internal wave phase speed $c=(g \alpha \Delta \Theta h /$ $\rho)^{1 / 2}=0.075 \mathrm{~m} \mathrm{~s}^{-1}$ (Figures 3a and $3 \mathrm{~b}$ ), for $\Delta \Theta=0.05^{\circ} \mathrm{C}$ across a "boundary thickness" $h=100 \mathrm{~m}$ roughly estimated from the thermistor string data (Figure 3c) and acceleration of gravity g. At 7 and $111 \mathrm{mab}$, the flow is Northwesterly, whereas at 215 mab the flow is northeast. Hence, the flow is upwelling favorable and up the promontory. The shear magnitude is larger between 111 and 216 mab than between 7 and 111 mab (Figure 3d). It is mainly in the u-component in the upper layer (Figures 3a, 3b, and $3 \mathrm{~d}$ ), and smaller than for the period of S-flow.

[11] During "S-flow," e.g. between days 390 and 470 , waters are $0.01^{\circ} \mathrm{C}$ warmer than average. This flow is downwelling favorable and down the promontory with $|\mathbf{U}|>$ c, a hydraulic supercritical flow. However, the $125 \mathrm{~m}$ scale near-bottom stratification is equivalent to or larger than during $\mathrm{N}$-flow. In the yearlong time mean and average over the vertical range of observations, these large scale $[\langle\mathrm{N}\rangle]=6.5 \times 10^{-4} \mathrm{~s}^{-1}$, upper layer $\left[<\left|\mathbf{S}_{\mathrm{u}}\right|>\right]=8.6 \times 10^{-4} \mathrm{~s}^{-1}$, and lower layer $\left[<\left|\mathbf{S}_{1}\right|>\right]=4.0 \times 10^{-4} \mathrm{~s}^{-1}$. The gradient Richardson number $R i=\mathrm{N}^{2} /|\mathbf{S}|^{2}$, the ratio of stability over destabilization, roughly varies around $R i=1$ (Figure $3 \mathrm{e}$ ) even though yearlong mean $[\langle R i\rangle] \approx 2.5$ and 10 for upper and lower layers, respectively. This implies marginal stability and turbulence is expected to occur occasionally, following the condition for stability for nonlinear (three dimensional) flows [Abarbanel et al., 1984].

[12] Over the yearlong period, the vertically averaged $\left\langle\varepsilon>\right.$ varies over five orders of magnitude, between $10^{-12}$ and $10^{-7} \mathrm{~W} \mathrm{~kg}^{-1}$ (Figure 3f), around its yearlong and vertical mean value of $[\langle\varepsilon\rangle]=6 \pm 3 \times 10^{-10} \mathrm{~W} \mathrm{~kg}^{-1}$ (the associated $\left[<\mathrm{K}_{\mathrm{z}}>\right]=2.7 \pm 1.4 \times 10^{-4} \mathrm{~m}^{2} \mathrm{~s}^{-1}$ ). The variation of $\varepsilon$ with time reflects the burst character of turbulence. The range of this variation is larger than that of $|\mathbf{S}|$ and much larger than that of $N$ (e.g., Figure $3 \mathrm{~d}$ shows barely varying $N$, compared to $|\mathbf{S}|$ ). Only a very high power of $N$ ( $N^{8}$ is chosen somewhat arbitrarily) more or less visually compares with large-scale variations of $\langle\varepsilon\rangle$, but not for all periods and not at small scales. This demonstrated that the burst character of turbulence (dissipation rate) is mainly attributable to overturning scale variations and not to variations in stable density stratification. As a result, correlation between stratification and dissipation rate is insignificant at the $95 \%$ level.

[13] The shear magnitude (Figure 3d), especially that of the upper layer, represents the time variation of $\langle\varepsilon\rangle$ better than (high powers of) $N$. During periods of S-flow, $|\mathbf{S}|>N$ for the upper layer (Figure 3d), or $1 / R i>1$ (Figure $3 \mathrm{e}$ ) and ten times larger $\langle\varepsilon\rangle$ (Figure $3 \mathrm{f}$ ) than during $N$-flow, on average. During periods of $N$-flow, $1 / R i<1$, implying relatively large stability.

[14] Although the yearlong mean large-scale stratification is relatively low, still $[\langle N\rangle]>>f=0.2 \times 10^{-4} \mathrm{~s}^{-1}$ the local inertial frequency (Figure 4). This implies that the (traditional) internal wave band is more than a decade wide in frequency $(\sigma)$. Despite relatively large noise levels, the above internal wave bounds are confirmed in current spectra and the spectrum of $\log \langle\varepsilon\rangle$ drops off steadily at a rate of $\sigma^{-1}$ until it deviates to a lower fall-off rate at $\sigma=3 N \approx$ $N_{\max }$, the maximum thin-layer buoyancy frequency. The differing turbulence depending on throughflow direction is demonstrated in detailed case studies for two typical periods (Figures 5 and 6). 

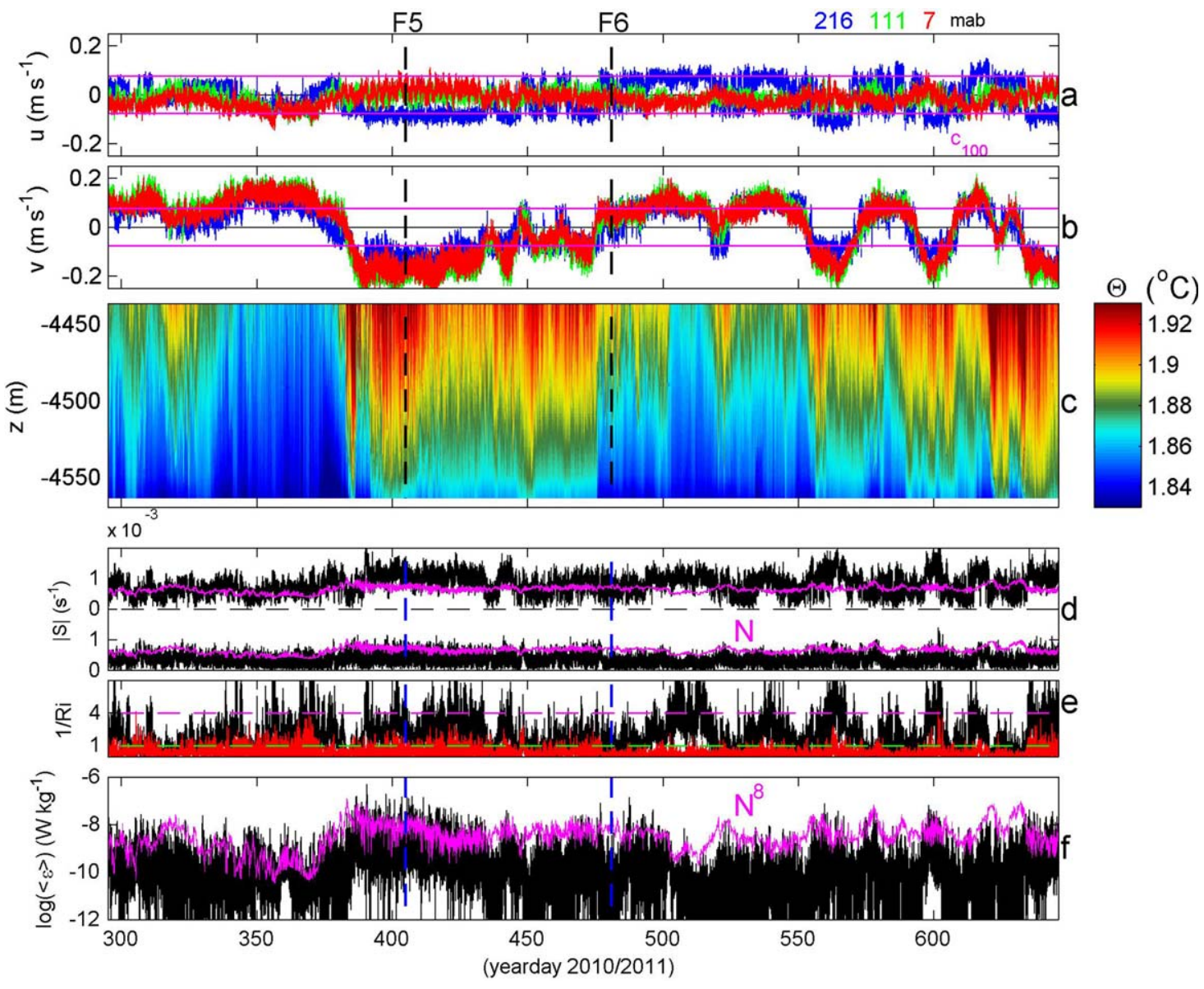

Figure 3. Overview of yearlong moored near-bottom observations: (a) Time series of East-West, $\sim$ cross-channel current component at 216, 111, $7 \mathrm{~m}$ above the bottom (mab). Purple lines indicate estimates of mode-1 internal wave phase speeds for a layer of $100 \mathrm{~m}$. (b) Corresponding North-South, along-channel component. (c) Depth-time series of conservative temperature from $631 \mathrm{~Hz}$ sampling sensors between [6, 132] mab. (d) Shear magnitude (black) over (top) 111-216 mab and (bottom) 7-111 mab. Buoyancy frequency from $\Theta$ over 6-132 mab (purple). (e) Inverse gradient Richardson number for $N$ over 6-132 mab with $|\mathbf{S}|$ over 111-216 mab (black) and 7-111 mab (red). Dashed lines indicate stability thresholds for nonlinear (green) and linear (purple) flows above which instability occurs. (f) Time series of vertically averaged $\langle\varepsilon\rangle$ (black) and arbitrary high-power $N^{8}$ (purple).

[15] During S-flow, the turbulence character is of the shear-(vertical) convection type, with relatively rapidly varying, short-lived motions and large vertically extending overturns (Figure 5). Over this two-day period, mean values are $[<\varepsilon>]=2.1 \pm 1 \times 10^{-9} \mathrm{~W} \mathrm{~kg}^{-1}$ and $\left[<\mathrm{K}_{\mathrm{z}}>\right]=7 \pm 4 \times 10^{-4} \mathrm{~m}^{2} \mathrm{~s}^{-1}$, while $[\langle N\rangle]^{2}=4 \times 10^{-7}$ $\mathrm{s}^{-2},\left[<\left|\mathbf{S}_{\mathrm{u}}\right|>\right]^{2}=1.1 \times 10^{-6} \mathrm{~s}^{-2}$, and $\left[<\left|\mathbf{S}_{1}\right|>\right]^{2}=2 \times 10^{-7}$ $\mathrm{s}^{-2}$. The $2 \mathrm{~m}$ sensor-separation is adequate to estimate turbulence parameters given the 10's-of-meters-high overturns (Figure $5 \mathrm{~d}$ ). The thin plumes extend very close to the bottom, which is not reached however (Figures $5 \mathrm{~b}-5 \mathrm{f}$ ). The duration of the motions, $<600 \mathrm{~s}$, is much smaller than the smallest internal wave period of approximately $T_{N \max } \approx$ $3000 \mathrm{~s}$ observed in layers $<10 \mathrm{~m}$ in thickness. Thus, these plumes provide evidence of convective overturning, initially shear-induced by larger-scale (inertial and subinertial) flow.

[16] During $N$-flow, the turbulence character is of the internal wave stratified shear flow type, with relatively slowly varying high-frequency internal wave motions and overturns spread-out "horizontally" along isopycnals (Figure 6). Over this two-day period, mean values are $[<\varepsilon>]=6 \pm 3 \times 10^{-11} \mathrm{~W} \mathrm{~kg}^{-1}$ and $\left[<\mathrm{K}_{\mathrm{z}}>\right]=4 \pm 2 \times$ $10^{-5} \mathrm{~m}^{2} \mathrm{~s}^{-1}$, which is more than an order of magnitude smaller than in Figure 5 (compare Figures 6a and 6e with Figures $5 \mathrm{a}$ and $5 \mathrm{e})$. The associated $[\langle N\rangle]^{2}=5 \times 10^{-7}$ $\mathrm{s}^{-2},\left[<\left|\mathbf{S}_{\mathrm{u}}\right|>\right]^{2}=5 \times 10^{-7} \mathrm{~s}^{-2}$, and $\left[<\left|\mathbf{S}_{1}\right|>\right]^{2}=1 \times 10^{-7}$ $\mathrm{s}^{-2}$. The $<10 \mathrm{~m}$ overturns are barely resolved by the sensor separation (Figure 6d). They remain relatively far from the bottom and are bound above and below by thin stratified layers. The periodicity of the naturally, by any flow disturbance, generated short-scale internal wave motions is $\sim 3000$ $\mathrm{s}$, commensurate the thin layer stratification (Figures $6 \mathrm{~b}$ and $6 \mathrm{c}$ ). Different stages of Kelvin Helmholtz billows that have a duration of typically $1000 \mathrm{~s}$ are superposed on these waves (Figures $6 \mathrm{c}$ and $6 \mathrm{f}$ ). Such periods are smaller than those of the high-frequency internal waves, but considerably larger than those of the convection during S-flow. For 


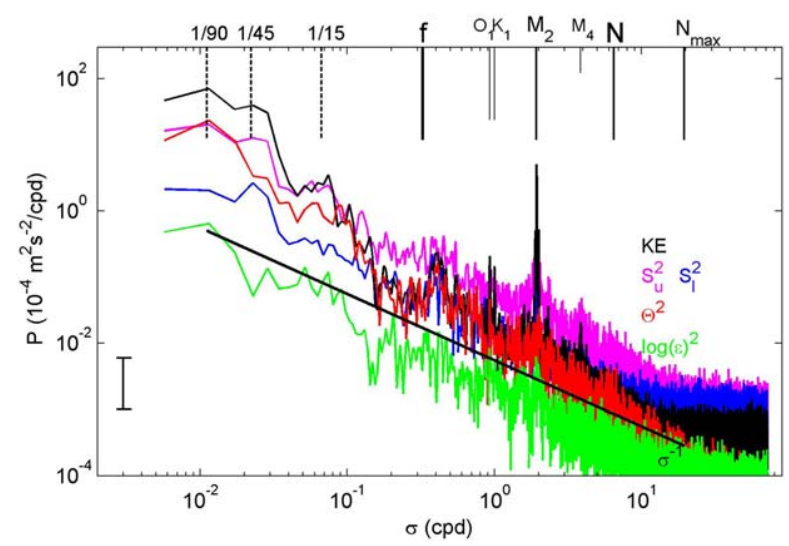

Figure 4. Yearlong spectra of kinetic energy (black) at $4470 \mathrm{~m}$, with $\left|\mathbf{S}_{\mathrm{u}}\right|^{2}$ over 4353-4458 m (blue) and $\left|\mathbf{S}_{1}\right|^{2}$ over 4458-4562 m (purple) (both: arbitrary scale in $\mathrm{s}^{-2} / \mathrm{cpd}$ ), $\Theta^{2}$ (red; arbitrary scale in ${ }^{\circ} \mathrm{C}^{2} / \mathrm{cpd}$ ) at $4470 \mathrm{~m}$ and $\log$ $\langle\varepsilon\rangle^{2}$ (green, arbitrary scale in $\mathrm{W}^{2} \mathrm{~kg}^{-2} / \mathrm{cpd}$ ) averaged over the range $4438-4563 \mathrm{~m}$. the N-flow, the billows clearly evidence (high-frequency) internal wave shear-induced overturning.

\section{Discussion}

[17] Although the currents at 7 mab reach values of $0.25 \mathrm{~m} \mathrm{~s}^{-1}$, the observed turbulence is not primarily associated with bottom friction (above a flat seafloor). This may be partially due to the lowest temperature sensor being 6 mab, although it is noted that there may be frictional influence as boundary layers can grow tens of meters high above sloping topography [e.g., Lentz and Trowbridge, 1991; Garrett et al., 1993]. Indeed, the observed distinctly different turbulence regimes are related to the direction of throughflow, the largest occurring during downwelling, down a hill-promontory (S-flow; average over ensemble of these periods: $\left.[\langle\varepsilon\rangle]=1.3 \pm 0.5 \times 10^{-9} \mathrm{~W} \mathrm{~kg}^{-1}\right)$, the smallest during up-hill, upwelling favorable (N-flow; average over ensemble of these periods: $[\langle\varepsilon\rangle]=1.1 \pm 0.5 \times$ $10^{-10} \mathrm{~W} \mathrm{~kg}^{-1}$ ). These turbulence parameter estimates are not very high compared with estimates near the bottom in the Romanche Fracture Zone [Polzin et al., 1996] and near

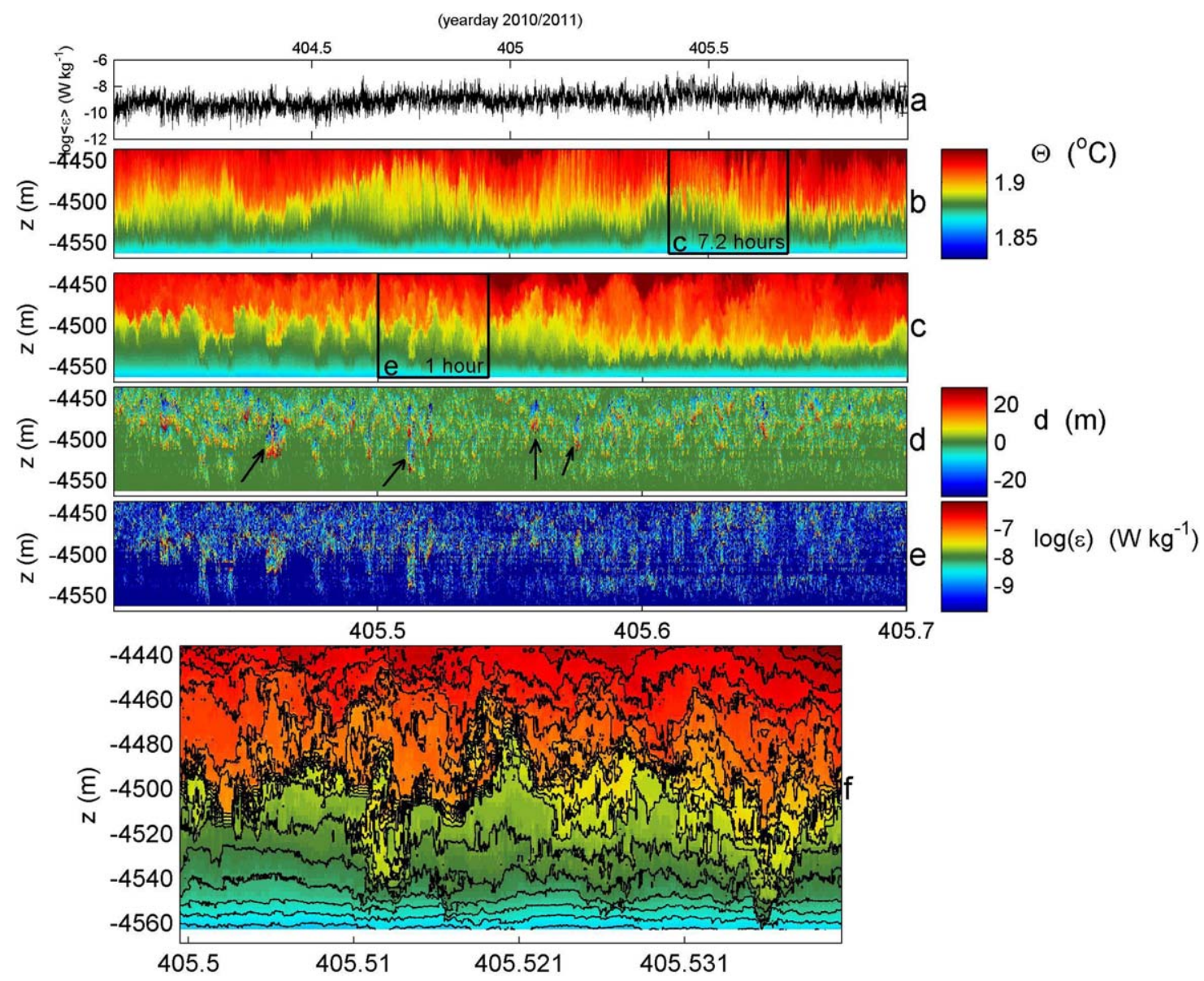

Figure 5. Two days of south(east)ward, downgoing flow, with relatively large $100 \mathrm{~m}$ scale shear, low $R i$, and strong convective turbulence: (a) time series of $\langle\varepsilon\rangle$, (b) depth-time series of $\Theta$, (c) $7.2 \mathrm{~h}$ of rectangle in Figure 5b, and (d) depth-time series of displacements from data in Figure 5c. The arrows indicate examples of large $(>10 \mathrm{~m})$ overturn displacement in the form of vertical plumes. (e) Dissipation rate from data in Figure $5 \mathrm{c}$ and (f) One hour of rectangle in Figure 5c, with black contours every $0.004^{\circ} \mathrm{C}$. 


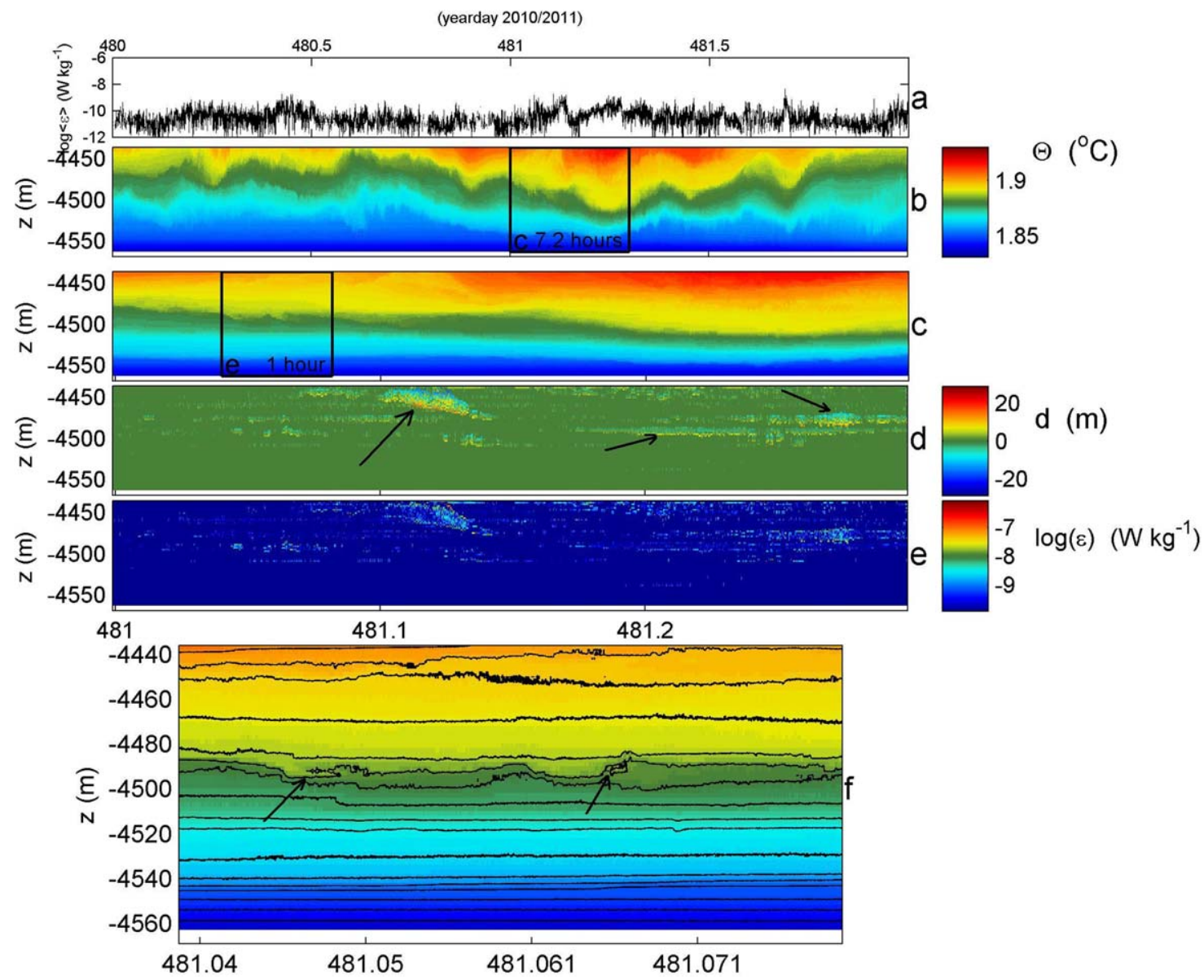

Figure 6. As Figure 5 with the same color ranges and (f) the same contour intervals, but for a period of north(west)ward, upgoing flow, with relatively low $100 \mathrm{~m}$ scale shear, high $R i$, and weak convective turbulence, but more important small-scale shear-induced overturning. (d) The arrows indicate examples of small moderate $(<10 \mathrm{~m})$ overturn displacements, which have considerable duration in time of 1000 2000 s. (f) Two initiating, small Kelvin-Helmholtz billows are indicated by arrows.

the summit of Great Meteor Seamount [van Haren and Gostiaux, 2012], but they are an order of magnitude larger than estimates for the ocean interior, e.g., Polzin et al. [1996]. They are thus important for mixing of AABW in the Kane Gap. The strong time variability of $\varepsilon$ is better represented by (100 m scale) $|\mathbf{S}|$ than by $N$, confirming previous suggestions for the importance of internal wave shear [Pinkel and Anderson, 1997].

[18] Although single $(125 \mathrm{~m}, 1 \mathrm{~Hz})$ profiles of $\varepsilon$ vary over several decades with time, their tendency toward equilibrium values is rather quick when averaged over a time scale $\mathrm{O}(100-1000) \mathrm{s}$ that resolves the largest overturn scales. As an example, the average $[\langle\varepsilon\rangle]$-values for the plots Figures $4 \mathrm{a}$ (2 days), 4e (7.2 h) and the equivalent for Figure $4 \mathrm{f}(1 \mathrm{~h})$ differ by $<30 \%$. For comparison, a freefalling microstructure profiler shows similar variability over several decades with time (and in the vertical; e.g., Polzin et al. [1996]). As such an instrument takes $200 \mathrm{~s}$ to cover $125 \mathrm{~m}$, compared to the present quasi-instantaneous sampling, a natural averaging over the larger overturn scales is performed automatically by the profiler. Given the profiler's fast sampling rate of $\mathrm{O}(100 \mathrm{~Hz})$, the average of a few of its profiles is sufficient to provide the same level of error as given above over bulk ranges like a "boundary layer height."

[19] The present observations contrast with the model of inverse relationship between $\mathrm{N}$ and turbulence, especially $\mathrm{K}_{\mathrm{z}}$ [Denman and Gargett, 1983]. This relationship is generally not found here, except during brief moments of time. The observations also contrast with large-scale flow rotational controlled ("Ekman") frictional boundary layers, which are conjectured to be ten times, $\mathrm{O}(10) \mathrm{m}$ versus $\mathrm{O}(1) \mathrm{m}$, larger for downwelling favorable flow compared to upwelling favorable flow [e.g., Garrett et al., 1993]. Here, we do observe strongest turbulence during downwelling favorable flow, but the stratification is as large as and reaches as close to the bottom as during upwelling favorable flow. This disagreement with the theory on large-scale flows is attributable to effects of smaller-scale topography, creating more turbulence during downgoing flow, and to internal waves that cause overturning and also restratification in thin layers by their movements up and down the slope. Compared with the tidally dominated Great Meteor Seamount, strongest turbulence is also found during the downslope phase but strong turbulence by an upslope bore is missing here, presumably by a lack of generation of 
solitary waves away from the topography [Vlasenko and Hutter, 2002].

[20] The near-bottom turbulence is thus found to vary at several unusual time scales. First, the large-scale variation having peak periods of $90+, 45$, and 15 days, which suggests a near-bottom internal seiche or effects of mesoscale eddies. It is unclear however, which (stratified) basin is driven to near-resonance and why the resonance is forced to a higher mode. The smallest period of 15 days has also been observed in the Romanche Fracture Zone [Mercier and Speer, 1998]. A simple calculation of an internal seiche period gives $T_{s}=2 L / n\left(g^{\prime} h\right)^{0.5}$, in which $\mathrm{L}$ denotes the characteristic horizontal scale of the basins North and South of the throughflow, $n$ is the mode number, $g^{\prime}=g \Delta \rho / \rho$. For the Kane Gap $h=100 \mathrm{~m}$ and mean $N\left(\Delta \rho=0.004 \mathrm{~kg} \mathrm{~m}^{-3}\right)$, we find $L \approx 120 \mathrm{~km}$ for a mode $n=1$ seiche of $T_{s}=45$ days. Likewise, although local mode-2 internal waves are observed at small scales, e.g. around day 404.65 in Figure 5 , no such mode is observed in large-scale variations (Figure 3). This requires further study, which should include mesoscale eddies.

[21] Second, near-inertial period variations of about 3 days are discernible in the present data, especially in isopycnal variations (Figure 3c). Near-inertial internal waves are known to generate large shear, because their vertical length scale is small [e.g., LeBlond and Mysak, 1978]. Their shear is near-circular in well-developed stratification, resulting in a near-constant shear amplitude that varies slowly with time [van Haren, 2000]. The present (100 m scale!) shear-spectra indeed show a hump at $\sigma \approx 1.1 \mathrm{f}$, similar to temperature variance, in addition to subinertial "peaks" (Figure 4). The latter are different for shear in the upper and lower layers. Although tidal flows are relatively strong, they are vertically coherent suggesting they are dominated by barotropic motions, which is confirmed from their narrow-peaked kinetic energy spectra and from their shear spectra that are reduced compared to the values near f. The local topography is subcritical for internal tides, which thus radiate upward and outward. An (internal) tidal peak is not well visible in $\Theta$ and $\varepsilon$ spectra.

[22] Thus, a combination of high-frequency internal waves with low-frequency near-inertial and subinertial motions creates unusual differences in near-bottom turbulence in the Kane Gap. The mixing during S-flow extends $130 \mathrm{mab}$, thereby affecting the throughflow of AABW most. Due to continuous restratification mainly by internal wave motions this mixing is relatively efficient.

[23] Acknowledgments. The project RUSNL10 (coordinator L. Maas) was financed in part by the Netherlands Organization for the advancement of scientific research (NWO). We thank captains and crews of R/Vs Ak. Ioffe and Ak. Sergey Vavilov for their assistance. We thank Martin Laan for the development of NIOZ-thermistors and mooring preparation.

\section{References}

Abarbanel, H. D. I., D. D. Holm, J. E. Marsden, and T. Ratiu (1984), Richardson number criterion for the nonlinear stability of threedimensional stratified flow, Phys. Rev. Lett., 52, 2352-2355.

Bonnin, J., H. van Haren, P. Hosegood, and G.-J. A. Brummer (2006), Burst resuspension of seabed material at the foot of the continental slope in the Rockall Channel, Mar. Geol., 226, 167-184.

Denman, K. L., and A. E. Gargett (1983), Time and space scales of vertical mixing and advection of phytoplankton in the upper ocean, Limnol. Oceanogr., 28, 801-815.

Dillon, T. M. (1982), Vertical overturns: A comparison of Thorpe and Ozmidov length scales, J. Geophys. Res., 87, 9601-9613.

Galbraith, P. S., and D. E. Kelley (1996), Identifying overturns in CTD profiles, J. Atmos. Oceanic Technol., 13, 688-702.

Garrett, C., P. MacCready, and P. Rhines (1993), Boundary mixing and arrested Ekman layers: Rotating stratified flow near a sloping boundary, Annu. Rev. Fluid Mech., 25, 291-323.

Hibiya, T. (1988), The generation of internal waves by tidal flow over Stellwagen Bank, J. Geophys. Res., 93, 533-542.

Hosegood, P., and H. van Haren (2003), Ekman-induced turbulence over the continental slope in the Faeroe-Shetland Channel as inferred from spikes in current meter observations, Deep Sea Res., Part I, 50, 657-680.

Klymak, J. M., and J. N. Moum (2003), Internal solitary waves of elevation advancing on a shoaling shelf, Geophys. Res. Lett., 30(20), 2045, doi:10.1029/2003GL017706.

LeBlond, P. H., and L. A. Mysak (1978), Waves in the Ocean, 602 pp., Elsevier, Amsterdam, NL.

Lentz, S. J., and J. H. Trowbridge (1991), The bottom boundary layer over the northern California shelf, J. Phys. Oceanogr., 21, 1186-1201.

Mercier, H., and K. G. Speer (1998), Transport of bottom water in the Romanche fracture zone and the chain fracture zone, J. Phys. Oceanogr., 28, 779-790.

Morozov, E., A. Demidov, R. Tarakanov, and W. Zenk (2010), Abyssal Channels in the Atlantic Ocean: Water Structure and Flows, 266 pp., Springer, Dordrecht, Netherlands.

Oakey, N. S. (1982), Determination of the rate of dissipation of turbulent energy from simultaneous temperature and velocity shear microstructure measurements, J. Phys. Oceanogr., 12, 256-271.

Osborn, T. R. (1980), Estimates of the local rate of vertical diffusion from dissipation measurements, J. Phys. Oceanogr., 10, 83-89.

Pinkel, R., and S. Anderson (1997), Shear, strain, and Richardson number variations in the thermocline. Part I: Statistical description, J. Phys. Oceanogr., 27, 264-281.

Polzin, K. L., K. G. Speer, J. M. Toole, and R. W. Schmitt (1996), Intense mixing of Antarctic Bottom Water in the equatorial Atlantic Ocean, $\mathrm{Na}$ ture, 380, 54-57.

Smith, W. H. F., and D. T. Sandwell (1997), Global seafloor topography from satellite altimetry and ship depth soundings, Science, 277, 19571962.

Thorpe, S. A. (1977), Turbulence and mixing in a Scottish loch, Philos. Trans. R. Soc. London A, 286, 125-181.

Thorpe, S. A. (1987), Transitional phenomena and the development of turbulence in stratified fluids: A review, J. Geophys. Res., 92, 5231-5248.

van Haren, H. (2000), Properties of vertical current shear across stratification in the central North Sea, J. Mar. Res., 58, 465-491.

van Haren, H., and L. Gostiaux (2012), Detailed internal wave mixing observed above a deep-ocean slope, J. Mar. Res., 70, 173-197.

van Haren, H., M. Laan, D.-J. Buijsman, L. Gostiaux, M. G. Smit, and E. Keijzer (2009), NIOZ3: Independent temperature sensors sampling yearlong data at a rate of $1 \mathrm{~Hz}$, IEEE J. Oceanic Eng., 34, 315-322.

Vlasenko, V., and K. Hutter (2002), Numerical experiments on the breaking of solitary internal waves over a slope-shelf topography, J. Phys. Oceanogr., 32, 1779-1793.

Weatherly, G. L., and P. J. Martin (1978), On the structure and dynamics of the oceanic bottom boundary layer, J. Phys. Oceanogr., 8, 557-570. 